\title{
GALERÍA HISTÓRICA DE POCOCÍ, ENMARCANDO NUESTRA MEMORIA
}

\author{
Rosa Julia Cerdas González \\ Universidad de Costa Rica \\ Jeremías Mora Muñoz \\ Universidad de Costa Rica
}

Recibido: 1-10-2016

Aprobado: 22-11-2016

Rosa Julia Cerdas González.
Graduada de Maestría en
Administración de Negocios, de la
Universidad por Costa Rica y
Maestría en Gestión de Turismo
Sustentable por la Universidad
Nacional.
Actualmente es Directora del
Recinto Universitario de la
Universidad de Costa Rica en
Guápiles. Ha trabajado en
proyectos de Gestión Cultural
desde hace más de ocho años. Es
miembro activo de la Red de
Manifestaciones Culturales de
Pococíy Guácimo.
Rosa.cerdas@ucr.ac.cr

que estuvieran interesados

\begin{abstract}
Resumen
Este artículo describe cómo se creó una exposición itinerante de doce obras artísticas, que fueron elaboradas por artistas plásticos, para dar a conocer los principales hechos históricos que han conformado el cantón de Pococí, de la provincia de Limón. Para lograr un sentido de pertenencia y el fortalecimiento de la identidad en los miembros de la comunidad, al conocer sus raíces históricas.

La metodología empleada consistió en crear un panel de expertos que determinaran doce hechos históricos de relevancia para conformar el cantón. Posteriormente, se realizó una identificación de artistas plásticos de la región en participar del proyecto. Luego se asignaron los hechos históricos que sirvieron de inspiración para los artistas y para la construcción de la Galería Histórica de Pococí. Conjuntamente, se efectuó una revisión bibliográfica para la elaboración de resúmenes que acompañan cada una de las obras y describiesen los momentos históricos.

Entre los resultados se detectó la existencia de un vacío en la población cantonal acerca de las raíces culturales e históricas de Pococí, el cual se espera llenar con la exposición itinerante de la galería histórica presentada en este artículo. Se logró la visualización de los artistas plásticos por parte de la comunidad. También la valoración de sí mismos como un colectivo que lucha por el fomento de las artes plásticas en la comunidad. Además, se logró la
\end{abstract} recopilación de diferentes materiales históricos que permitirán generar otros productos de naturaleza didáctica, para ser empleados en la trasmisión de una parte del conocimiento histórico sobre Pococí.

Palabras clave: Patrimonio cultural, investigación histórica, identidad cultural, memoria colectiva, material visual.

\begin{abstract}
This article describes the creation of an itinerant exposition with twelve artistic works, which were elaborated by plastic artists to depict the main historical facts that have
\end{abstract}


conformed the canton of Pococí in the province of Limón. The main objective of this exposition was to enhance a sense of belonging and strengthen the identity of the communal members by acknowledging their historical roots.

The selected methodology consisted in creating a panel of experts who determined twelve relevant historical facts for the constitution of the canton. Afterwards, an identification of the plastic artists of the region who would be interested in participating in the project was determined. Likewise, the historical facts used to inspire artists and the construction of the Historical Gallery of Pococí were assigned. Simultaneously, a bibliographical review for writing summaries that would be included to accompany each work and describe the historical moments was carried out.

Among the main results, the investigators detected an existent emptiness among the cantonal population about the cultural and historical roots of Pococí. Hence, the itinerant exposition of the historical gallery described in this article attempts to inform its viewers about the selected cultural and historical facts, enhancing people's cultural and historical awareness of their canton. Furthermore, thanks to the gallery, the plastic artists were introduced to the local community and the appreciation of their role as a collective group eager to fight for the encouragement of plastic arts in the community was supported. Finally, various historical materials were compiled, pertaining the generation of other didactic products to be employed in the transference of one part of the historical knowledge of Pococí.

Keywords: cultural heritage, historical research, cultural identity, collective memory, visual material

\section{INTRODUCCIÓN}

En momentos en que la globalización se cierne sobre todas las comunidades de nuestro país -alejándonos de nuestras raíces y "conociendo" más de otras culturas que de la nuestra- se nos plantea de forma imperativa el desafío de realizar esfuerzos para recuperar y valorar nuestra herencia; además de construir en colectividad un tejido donde nos concibamos como parte de un todo mayor.

En el caso particular de este proyecto, fue desarrollado en el cantón de Pococí, segundo cantón de la Provincia de Limón, cuenta con una superficie de $2.403,49 \mathrm{~km} 2$ y se ubica en una altitud media de 262 m.s.n.m. Sus límites administrativosterritoriales del son: al norte con Nicaragua y el Mar Caribe; al sur con los cantones vecinos de Guácimo, Siquirres, Turrialba y Oreamuno; al este con el Mar Caribe; y al oeste con los cantones de Sarapiquí y Vázquez de Coronado (Municipalidad de Pococí 2013). Además, la población aproximada que se asienta en Pococí - de acuerdo con los datos del censo de 2011 - es de 125.962 habitantes (INEC 2011: 49), cifra que pudo haber variado levemente en los últimos cuatro años.

Este proyecto partió de una necesidad que se desprende del alejamiento de nuestras raíces culturales e identitarias como habitantes de Pococí, así como, a la paulatina sustitución de lo 
autóctono por lo foráneo. De ahí que la problemática principal radica en la poca disposición que tienen las generaciones más jóvenes para aprender sobre la cultura y la historia de la localidad donde habitan, y por ende, no se logra una identificación o sentido de pertenencia a los rasgos propios de sus territorialidades. Uno de los aspectos que se trató en este proyecto fue, sin duda alguna, la cultura y la influencia de esta en la conformación de identidades en los pueblos. De acuerdo con la tesis manejada por Molano (2007), la cultura es uno de los tantos elementos que da vida a los seres humanos, y en ella se ven englobadas las tradiciones, creencias, costumbres, el conocimiento, los códigos éticos y morales; además, a través de la cultura se puede generar: cohesión social, un modo de vivir, riqueza y empleo, y estabilidad territorial.

En instancias mayores, la UNESCO indica que "es la cultura la que ofrece el contexto, los valores, la subjetividad, las actitudes y las aptitudes sobre las que los procesos de desarrollo han de tener lugar" (UNESCO Etxea 2010: 5). Asimismo, dicha entidad internacional considera que las culturas no son compendios de prácticas y valores estáticos y excluyentes entre sí; sino que dialogan entre ellas, y se recrean constantemente en tanto las personas cuestionan, adaptan y reconfiguran sus principios axiológicos y prácticas ante el cambio de la realidad y el intercambio de ideas (UNESCO Etxea 2010).

Teniendo en cuenta que el desarrollo cultural se homologa con el desarrollo económico y social de los pueblos, y que estos son codependientes entre sí; no se puede pretender la concepción de una cultura unificada o global, ya que no todos los pueblos presentan las mismas características y las mismas expectativas de desarrollo, que habitualmente conceptualizan aquellos países que se colocan en la cúspide mundial.

Al contrario, es de suma importancia reconocer la diversidad cultural existente entre diferentes localidades y territorios, pues es en ese aspecto donde radica un desarrollo humano más completo; lo anterior se contempla en el artículo 3 de la Declaración Universal de la UNESCO sobre la Diversidad Cultural:

[...] La diversidad cultural amplía las posibilidades de elección que se brindan a todos; es una de las fuentes del desarrollo, entendido no solamente en términos de crecimiento económico, sino también como medio de acceso a una existencia intelectual, afectiva, moral y espiritual satisfactoria. (UNESCO 2004: 4). 
Por otro lado, este proyecto abordó también el aspecto vinculado con la identidad cultural, como factor que se construye a partir del desarrollo de la cultura. La identidad como tal se puede concebir como la definición que construyen los individuos sobre sí mismos; y de acuerdo con Molano (2007: 3), como el sentimiento de pertenencia a una colectividad, un sector social, un pueblo, o a un grupo en específico.

Larraín (2003: 32) considera que la construcción de la identidad es un proceso cultural, material y social; cultural pues los individuos se definen a sí mismos basándose en ciertas categorías compartidas, tales como religión, género, clase, etnia, lenguaje, sexualidad etc.; material porque los seres humanos se proyectan simbólicamente a sí mismos en cosas perceptibles por los sentidos; y social porque la identidad implica una referencia a "los otros" en dos sentidos: primero, "los otros" son aquellos que emiten opiniones y expectativas sobre nosotros, que respectivamente internalizamos y asumimos como propias; segundo, "los otros" son aquellos de los cuales nos queremos diferenciar.

No obstante, para la construcción de la identidad cultural también se requiere de la historia. Pues "dicha identidad implica, por lo tanto, que las personas o grupos de personas se reconocen históricamente en su propio entorno físico y social" (Molano: 2007: 74).

De manera que, la historia como ciencia que estudia al ser humano en sociedad a través del tiempo (Bloch citado por LeGoff 2005: 26) contribuye con herramientas cognoscitivas para la construcción identitaria de los pueblos, en tanto se brindan perspectivas e interpretaciones -que a su vez no se desligan de las subjetividades- del pasado a través de los discursos históricos que plantean los historiadores.

Lo anterior evidencia la importancia del conocimiento de los aspectos históricos autóctonos locales en Pococí, porque aparte de lo fundamental que es el conocimiento histórico para el constructo identitario, la historia tiene el potencial transformador de la realidad presente y futura, en la medida que la población tenga acceso a dicho conocimiento; puesto que: "El estudio de la historia permitirá al ciudadano sensato establecer la pauta que el proceso ha ido entretejiendo en el pasado, y de allí deducir su probable desarrollo en el futuro próximo." (González: 2005: 70).

Dada la importancia del desarrollo de una identidad cultural en contextos de diversidad, y ligado estrechamente al conocimiento histórico local, este proyecto se desarrolló apegado a otros 
lineamientos y sugerencias propuestas por la UNESCO (2004: 42, 48), para fomentar una diversidad cultural en aras del desarrollo, como la elaboración de estrategias para preservación y valorización del patrimonio cultural de tipo material e inmaterial, y el apoyo a la movilidad de artistas, creadores, investigadores, científicos e intelectuales.

Se considera que a partir de proyectos con iniciativas de desarrollo cultural como las que propone este, se logrará fomentar un mayor desarrollo del aparato económico y social del cantón, porque:

\footnotetext{
[...] no sólo puede revivir, volver a poblar áreas rurales, despertar interés en una población apática, lograr cohesión social, sino que además puede desencadenar actividades económicas y con ello mejorar los ingresos y la calidad de vida de la colectividad. Usualmente estos ingresos están relacionados con la oferta de productos, bienes y servicios, que se colocan oportunamente en el mercado, que van desde lo agropecuario hasta actividades orientadas al turismo (Molano: 2007: 74).
}

Otro logro que se puede desprender de proyectos de esta naturaleza, de acuerdo con lo que se ha expuesto anteriormente, es el conocimiento de la historia local, y por ende se contribuye a la consolidación de una identidad cultural "pocociceña" más arraigada en lo propio. Sin dejar de lado el interés por la acción de mostrar una perspectiva más diversa a la población con respecto a las manifestaciones culturales y artísticas; y fomentar el apoyo y reconocimiento de las producciones artísticas e intelectuales autóctonas.

Por otra parte, es importante recordar que además del fundamento teórico existente para desarrollar un proyecto relacionado con la cultura y la identidad, existen también otros antecedentes que dieron origen a este, denominado Galería Histórica de Pococí, entre los que están: la organización del 1 Encuentro de Manifestaciones Culturales de Pococí, realizado en Julio del 2014, el cual fue organizado por la Oficina de Gestión Cultural en la provincia de Limón del Ministerio de Cultura y Juventud y la Universidad de Costa Rica, en el Recinto de Guápiles. En ese se discutió sobre aspectos varios relacionados con el fomento de la identidad de la población a través de las distintas manifestaciones artísticas presentes en el cantón de Pococí.

Además, se crea la comisión coordinadora de la Red de Manifestaciones Culturales de Pococí y Guácimo, la cual, basándose en las conclusiones del encuentro, define como uno de 
sus ejes de trabajo, difundir las diferentes manifestaciones artísticas, entre ellas la de los artistas plásticos.

En otra instancia, se cuenta con el apoyo de entidades estatales como la Universidad de Costa Rica, a través del Taller Comunitario de Artes y Oficios -que se desarrolla en el Recinto de Guápiles- y el Ministerio de Cultura, por medio de la Oficina de Gestión Cultural en Limón; que han contribuido en la investigación y difusión de diferentes actividades relacionadas con la cultura (ferias, encuentros, peñas culturales, ciclos de cine).

El sector cultura, compuesto por colectivos privados y públicos, ha externado como una preocupación el desconocimiento que existe de una gran parte de los habitantes de Pococí, acerca de sus raíces culturales e históricas. Esta situación ha influido en que aspectos relacionados con la manera de conformar la identidad del pueblo en relación con el desarrollo cantonal, que se muestra en la poca valoración de los patrimonios con que se cuenta.

El objetivo general que se persigue es crear una exposición itinerante acerca de la historia de Pococí hasta el año 2010 aproximadamente, reflejada en doce momentos históricos de relevancia para la conformación del territorio, con el fin de generar identidad y apego en los pobladores del cantón.

Adicionalmente, se pretende sensibilizar a los habitantes, a través de la apreciación de las obras plásticas y que la comunidad reconozca a los artistas locales, para que valore sus trabajos. A través de ello, se pretende el reconocimiento de nuestro Patrimonio Histórico, construido a partir de los productos artísticos, lo cual, fortalece nuestra capacidad de creación e innovación, en las diversas prácticas artísticas y culturales que se transmitan a los pobladores.

Se espera que la Galería Histórica de Pococí impacte profundamente en nuestra comunidad, que necesita un referente fundamentado y accesible para conocer sus propias raíces, de una forma que tanto los niños como los adultos; los habitantes con amplia formación académica, así como los más sencillos encuentren de forma accesible y veraz esta información. 


\section{METODOLOGÍA}

Para construir la galería se desarrollaron las siguientes actividades: primero se efectuó una revisión bibliográfica de autores nacionales que hubieran realizado trabajos históricos sobre el cantón de Pococí, lo que permitió ubicar diferentes momentos históricos que fueron relevantes en su conformación.

Adicionalmente, se trabajó en la recolección de historia oral mediante conversatorios denominados las Mesas de los Cien años, donde habitantes con más de 35 años de vivir en el cantón relataban su experiencia de vida, al trasladarse a Pococí, esto permitió otras perspectivas históricas que se complementaron con la parte documental y esta sirvió de insumo a los artistas.

Posteriormente, se conformó un panel de expertos, quienes en conjunto determinaron los momentos históricos más relevantes en la historia del cantón. Este material se segmentó en 12 momentos históricos importantes para la formación de lo que hoy día es Pococí, los cuales sirvieron de inspiración e insumo para que los artistas plásticos crearan sus obras.

Paralelo a esto, se identificó y se buscó a los pintores plásticos que residen en el cantón de Pococí. Para ello, se utilizaron las redes sociales, donde se hizo la convocatoria para participar en el proyecto. Adicionalmente, se revisaron las bases de datos con que contaba la Casa de la Cultura de Pococí, lo que permitió ubicar a algunos de los participantes. También se recurrió a los mismos artistas, los cuales hacían recomendaciones de otros colegas que conocían.

A medida que se iban localizando, se organizaron reuniones para explicar el objetivo de la galería y contar con su aprobación para participar en el proyecto. En dichas reuniones se registró por escrito el compromiso de los pintores para participar en el proyecto y asuntos adicionales tales como: la asignación del hecho histórico, la fecha de entrega de la obra, las dimensiones que tendría la obra y el consentimiento informado para uso de la imagen de la obra plástica, para ser utilizadas a la hora de confeccionar desplegables y un calendario para el año 2016.

Los artistas que finalmente contribuyeron en el proyecto fueron los siguientes: Rocío Venegas Chaverry, Marco Antonio Bogantes Granados, Manuel Sánchez Rojas, Mauricio Vargas Sequeira, Braulio Pérez Arias, Ana $\mathrm{M}^{\circ}$ Granados Cáseres, Paula Pamela Solano Alfaro, César Chacón Quirós, Patricia Erickson, José Alberto 
Pérez Arrieta "Copetilla", Randall Araya Villalobos y Lucía Arce Hernández.

Llegado este punto, los artistas tuvieron un lapso de aproximadamente ocho semanas para concluir sus obras, estas fueron entregadas para su enmarcado a finales del mes de Julio.

Posteriormente, se construyeron las fichas que dieron soporte a los textos históricos que acompañan la galería en un lenguaje amigable para el público, con el objetivo de despertar su curiosidad por saber más sobre la historia del cantón.

Las obras terminadas fueron fotografiadas por Wagner López Espinoza para realizar el diseño gráfico de 12 desplegables en los cuales se incluyó la obra plástica con su respectiva referencia documental, y datos relacionados al autor de la obra. La utilización de desplegables brinda la facilidad de que la galería se pueda exponer y transportar fácilmente a los diferentes espacios públicos dentro del cantón, sin el inconveniente de que las obras puedan sufrir deterioro en el transporte.

Una vez concluida esta fase se preparó la primera exposición de la Galería en el marco del 20 Aniversario del Recinto de Guápiles de la Universidad de Costa Rica. En ella, conforme con los objetivos establecidos, se programaron varios recorridos en los cuales, por medio de un expositor, se realizaba una visita guiada donde se narraba, obra por obra, el hecho histórico y la interpretación que el artista realizó de este. Es importante aclarar que las obras reflejan la interpretación del artista y no necesariamente corresponden a una representación del momento histórico. Dada la favorable acogida que tuvo la galería en dicha exposición, se planteó como proyecto a futuro la presentación de la galería en otros espacios del cantón.

Durante la segunda fase, en el año 2016, se realizarán las visitas a los centros educativos y espacios públicos del cantón. Para ello se contará con el aporte de voluntarios del Recinto de Guápiles de la Universidad de Costa Rica, quienes llevarán la Galería a los centros educativos de donde provienen. Durante esta visita se entregarán los calendarios que se confeccionaron tomando como base la información de la Galería. Es importante señalar que los fondos para la consecución de este proyecto fueron aportados por el Programa de Becas Taller del Ministerio de Cultura y Juventud de Costa Rica. 


\section{DESARROLLO}

A continuación se muestran los resúmenes históricos que acompañan a cada una de las obras de la galería histórica -en apego a la metodología ya explicada- en el orden en el cual se exponen. Además, se indica la técnica utilizada y datos básicos sobre el autor.

\section{Los pobladores precolombinos de Pococí}

Antes de la llegada de los europeos a territorio nacional, la población aproximada de Costa Rica sumaba las 400000 personas. Como característica general, las sociedades nativas costarricenses se organizaron en tribus y cacicazgos (Solórzano: 1997: 146). Las tribus eran formas simples de organización, normalmente compuestas por grupos familiares, mientras que los cacicazgos o señoríos tenían mayor complejidad, y varias comunidades eran controladas por una figura central denominada "cacique".

Pococí no fue la excepción, la zona en la que actualmente vivimos fue poblada por pueblos indígenas llamados Pococes. Estos pertenecían al Cacicazgo del Guarco -actualmente Cartago(Ibarra: 1986: 88), y junto a otros pueblos cercanos como Suerres y Chirripo, servían al Cacique Correque. Posiblemente, los indígenas Pococes subsistían mediante el cultivo de maíz, frijoles, chayotes, tacacos, ayotes, yuca, pejibayes, etc. ya que estos productos se sembraban casi en todos los cacicazgos costarricenses (Solórzano: 1997: 146), empleando el sistema de roza (tala y quema de una parte del bosque).

Es muy importante para nosotros comprender que, lo conocido sobre los pueblos antiguos en Costa Rica está sesgado por la visión europea. Dicha visión coloca a los indígenas como "los otros" quienes son inferiores ante los conquistadores, que se consideran a sí mismos superiores y civilizados.

La artista encargada de reflejar esta etapa de la historia del cantón, fue la señorita Lucía Arce Hernández. Ella utilizó una técnica mixta, de dibujo a lápiz y acrílico, lo cual se evidencia en la Figura N¹. Esta presenta unas dimensiones $60 \times 80 \mathrm{~cm}$. 


\section{Figura 1}

"Noche ancestral"

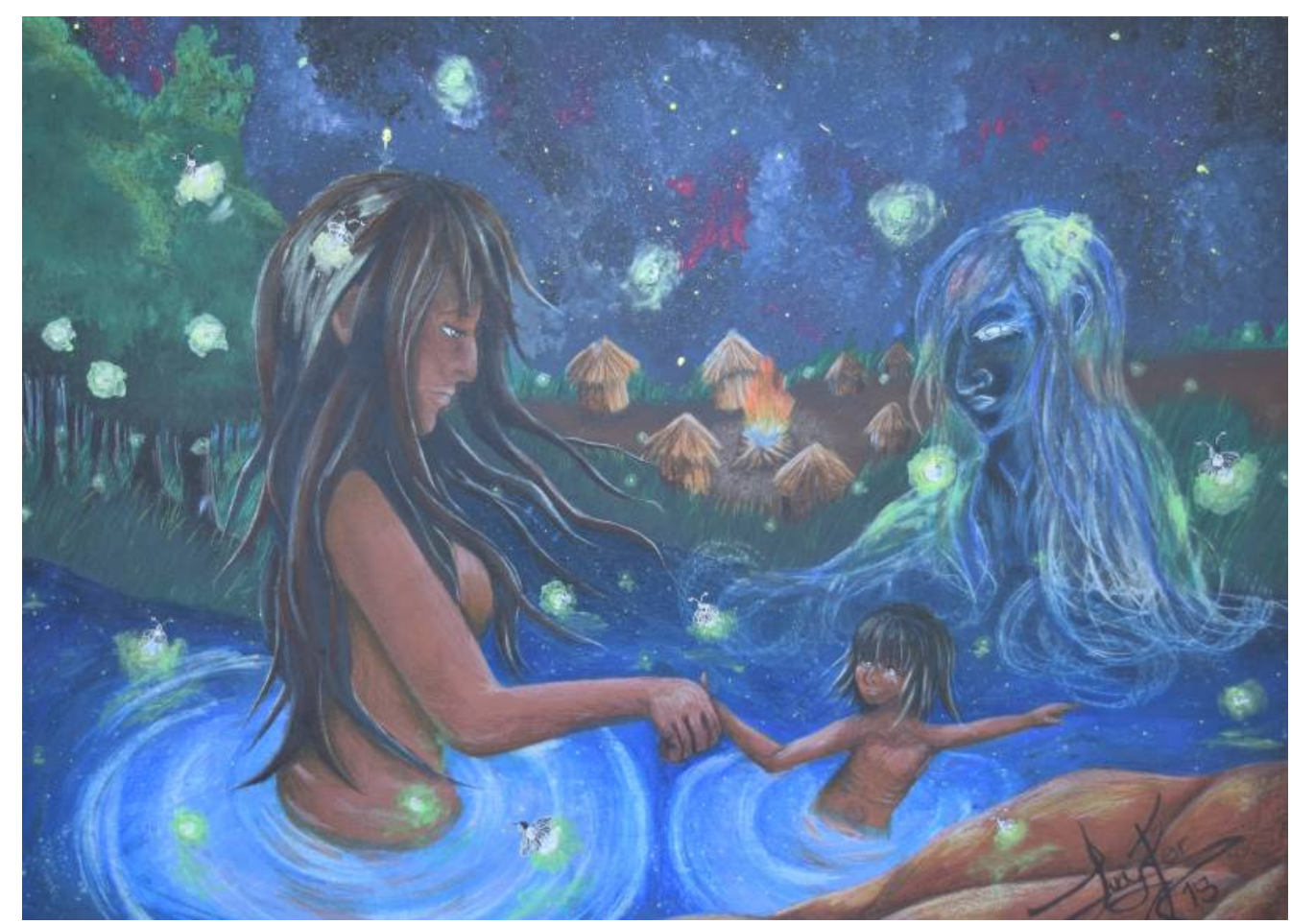

Fuente: Arce 2015 


\section{Construcción de la línea del ferrocarril}

En la década de 1870 Tomás Guardia llegó a la presidencia tras un golpe de Estado. Uno de los principales intereses de la administración de Guardia fue establecer una vía de comunicación a lo largo del país, con la finalidad de hacer más rápido y reducir costos en el transporte hacia el exterior, del café cultivado en el Valle Central (Viales: 2013: 97). La mejor opción para esto sería a través de ferrocarriles. De esta manera, para el año 1871 mediante el decreto número 34, se inició la construcción del ferrocarril que comunicaría Limón con Alajuela (Sáenz: 1911: 12). Por supuesto, Guápiles formaba parte de la ruta trazada por los ingenieros que construirían la obra ferroviaria.

La ruta que involucró a Guápiles, originalmente iría de Carrillo (poblado ubicado cerca del Río Sucio) hasta Siquirres, y mediría $53,19 \mathrm{~km}$. Sin embargo, debido a lo accidentado del terreno entre Carrillo y Guápiles, se decidió que la ruta se construiría desde Guápiles hasta Siquirres, midiendo tan solo 32,18 km (Sáenz: 1911: $8,14)$. La construcción costó aproximadamente 2 millones de colones, suma que para la época era demasiado grande. A este tramo entre Guápiles y Siquirres, del cual hoy todavía encontramos rastros, se le llamó "Línea Vieja". Y fue muy importante para el desarrollo de las bananeras y el comercio guapileño entre 1890 y mediados del siglo XX.

Para representar este momento histórico, la artista Rocío Venegas Chaverry utilizó una técnica de dibujo a lápiz que se puede observar en la Figura $\mathrm{N}^{\circ} 2$, la cual presenta unas dimensiones de $60 \times 80 \mathrm{~cm}$. 


\section{Figura 2}

"Vida alrededor del tren"

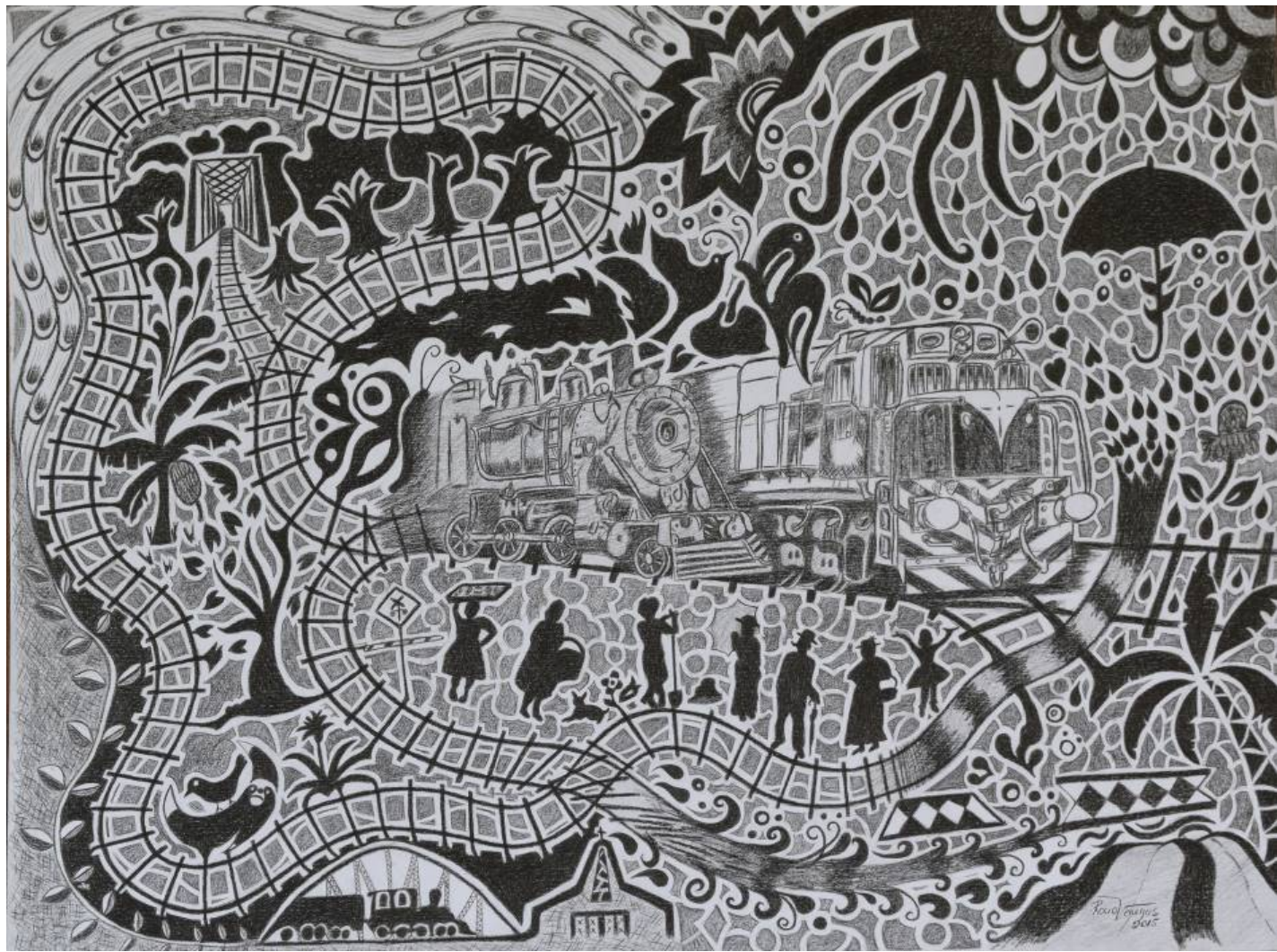

Fuente: Venegas 2015 


\section{Evolución de la educación primaria: Escuela Central de Guápiles}

La Escuela Central de Guápiles no siempre estuvo en el lugar donde se encuentra actualmente. La institución como tal se fundó en el año 1909, y funcionaba en un edificio ubicado en el actual Salón Parroquial -frente a la Oficina de Correos- (Araya, 2014).En el año 1951 la escuela fue incendiada, y dicho acto criminal quedó impune por falta de investigación. Debido a esto, se construyó un galerón provisional junto a las palmeras que adornaban la entrada a la casa administrativa de la compañía bananera (Jiménez: 1995: 10). Cuando la compañía se retiró de la zona, el terreno de las palmeras quedó prácticamente baldío. La Junta de Educación se movilizó y obtuvo fondos para comprar un terreno. Se le compraron dos hectáreas a Abelardo Alfaro.

Los terrenos donde se construyó el actual edificio escolar pertenecen a la municipalidad. Sin embargo, se llegó al acuerdo de hacer un intercambio de propiedades entre la Junta de Educación y la municipalidad (Jiménez: 1995: 10-11). El edificio construido no solo ha funcionado como escuela, también se utilizó durante un breve periodo como cuartel. En la torre del edificio se colocaron ametralladoras (Araya, 2014), esto con la finalidad de repeler posibles ataques de soldados de la oposición de la Guerra Civil de 1948.

Este momento histórico se puede apreciar en la Figura No3, la cual fue creada por el artista Marco Antonio Bogantes Granados, que utilizó una técnica de collage y acrílico. Su obra tiene unas dimensiones de $80 \times 60 \mathrm{~cm}$.

\section{Figura 3}

"Educación incompleta"

Fuente: Bogantes 2015

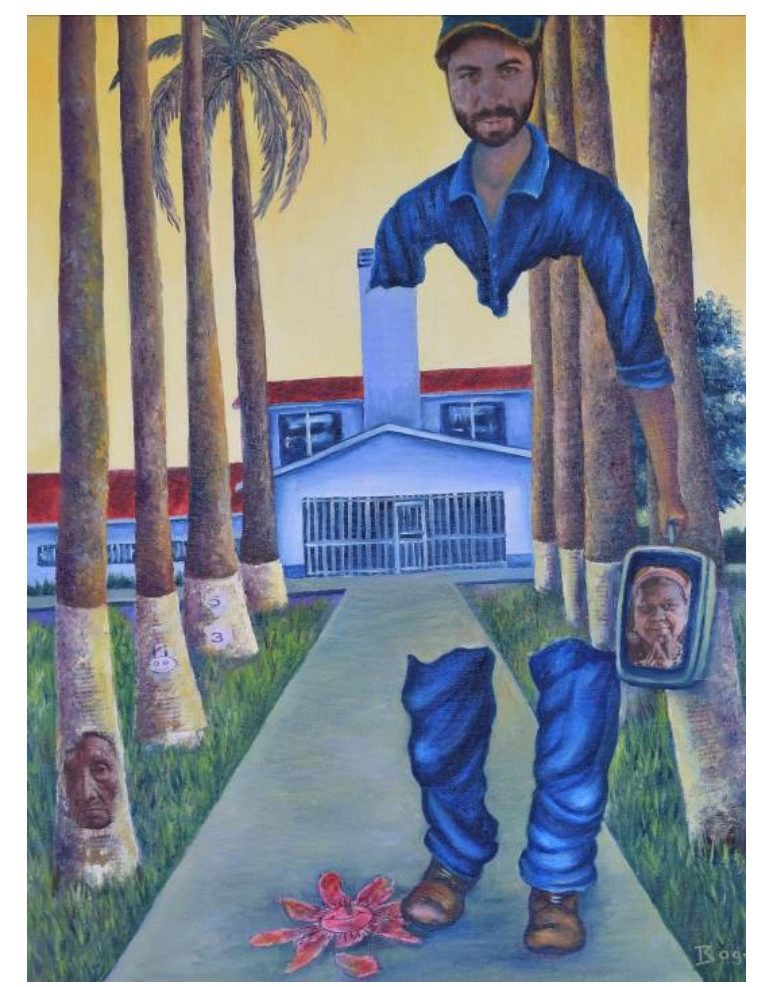




\section{Creación del Cantón de Pococí}

Pococí fue declarado cantón mediante la Ley No. 12 del 19 de setiembre de 1911 (ProDUS 2006: i), durante la administración del presidente Ricardo Jiménez Oreamuno. Debido a la intervención del Diputado Juan Bautista Quirós, quien acogió la solicitud de 4.626 vecinos firmantes de los poblados de Guápiles, Jiménez, Guácimo, Las Mercedes, Pocora, Germania, Cairo, Barra del Colorado y La Junta, de erigir el cantón de Pococí (Arias, 2011).

La solicitud de formar un cantón se dio porque los pobladores consideraban que la zona tenía las condiciones necesarias para serlo: templo católico, hospital, escuela, oficina central de teléfonos, oficina de correos y telégrafos, agencia de policía, estación de tren, planta eléctrica, producción bananera de millón y medio de racimos, entre otras (Arias 2011).

Los distritos que inicialmente conformaron el cantón eran: Guápiles, Jiménez, Guácimo, Las Mercedes y Pocora Oeste (Arias, 2011). Pero en la década de los setenta, Pococí sufre modificaciones y se establecen los límites definitivos con Sarapiquí; se crea el cantón de Guácimo al separarse de Pococí. Además, se crean los distritos de La Rita, Roxana, Cariari y Barra del Colorado (Cerdas: 2013: 365). Posteriormente, en el año 2012, Pococí se volvió a ordenar administrativamente con la creación del distrito de La Colonia, de manera que el territorio guapileño se redujo (Hernández, 2012).

El artista que representó este momento histórico fue el señor Manuel Sánchez Rojas, quien utilizó una técnica de acrílico y creó un producto que presenta unas dimensiones de $80 \times 60 \mathrm{~cm}$, el cual se puede contemplar en la Figura $\mathrm{N}^{\circ} 4$.

Figura 4

"Pococí"

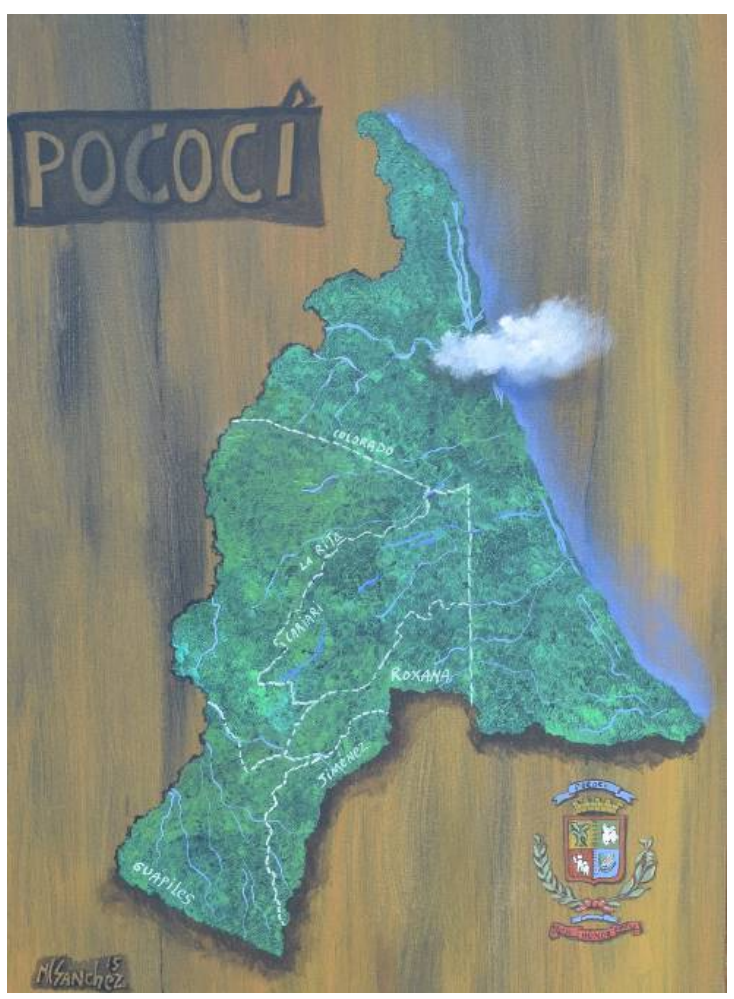




\section{Partida del enclave bananero de la United Fruit Company}

Para el año 1905, la United Fruit Company y los bananeros costarricenses alcanzaron su punto más alto de producción, pero entre 1910 y 1930 ocurrieron eventos que debilitaron la economía del banano en el Caribe costarricense. Por ejemplo, la propagación de enfermedades que afectaron a las plantaciones bananeras: sigatoka, moko y mal de Panamá (Viales y Montero: 2014: 333). También las inundaciones de 1922 y 1928, además de la gran crisis de 1929 y la depresión de los treintas (Borge: 2002: 12). Sin dejar de lado la crisis económica vivida durante la Primera Guerra Mundial.

Las enfermedades y las inundaciones provocaron que la producción de bananos aptos para exportar se redujera, mientras que las crisis económicas ocasionaron la baja en los precios de los bananos, que ya de por sí salía caro producir y mantener en la zona Atlántica. Otro factor que se debe tomar en cuenta, era la sobreexplotación del suelo por parte de la UFCO, además del uso de agroquímicos y tecnologías para combatir enfermedades del banano. Esto ocasionó el deterioro acelerado de los suelos caribeños y la baja calidad de los bananos.

La suma de todo lo mencionado indició a los dirigentes de la UFCO que se debían retirar del Atlántico. Por eso, desde 1930 la compañía comenzó a adquirir tierras en el Pacífico Sur costarricense. Ya para 1940, Pococí y la provincia de Limón habían sido abandonados. Durante los años cuarenta y los cincuenta, lo que se conoce como Línea Vieja, apenas era habitado por unos cuantos campesinos costarricenses que tenían fincas propias; y los afrodescendientes que vivían alrededor de las vías del ferrocarril (Borge: 2002: 19).

Este momento de la historia del cantón se ve reflejado en la Figura $N^{\circ} 5$, que corresponde a la obra de Braulio Pérez Arias, el cual utilizó una técnica de acrílico y su obra posee dimensiones de $60 \times 70 \mathrm{~cm}$. 


\section{Figura 5}

"Sueños rotos"

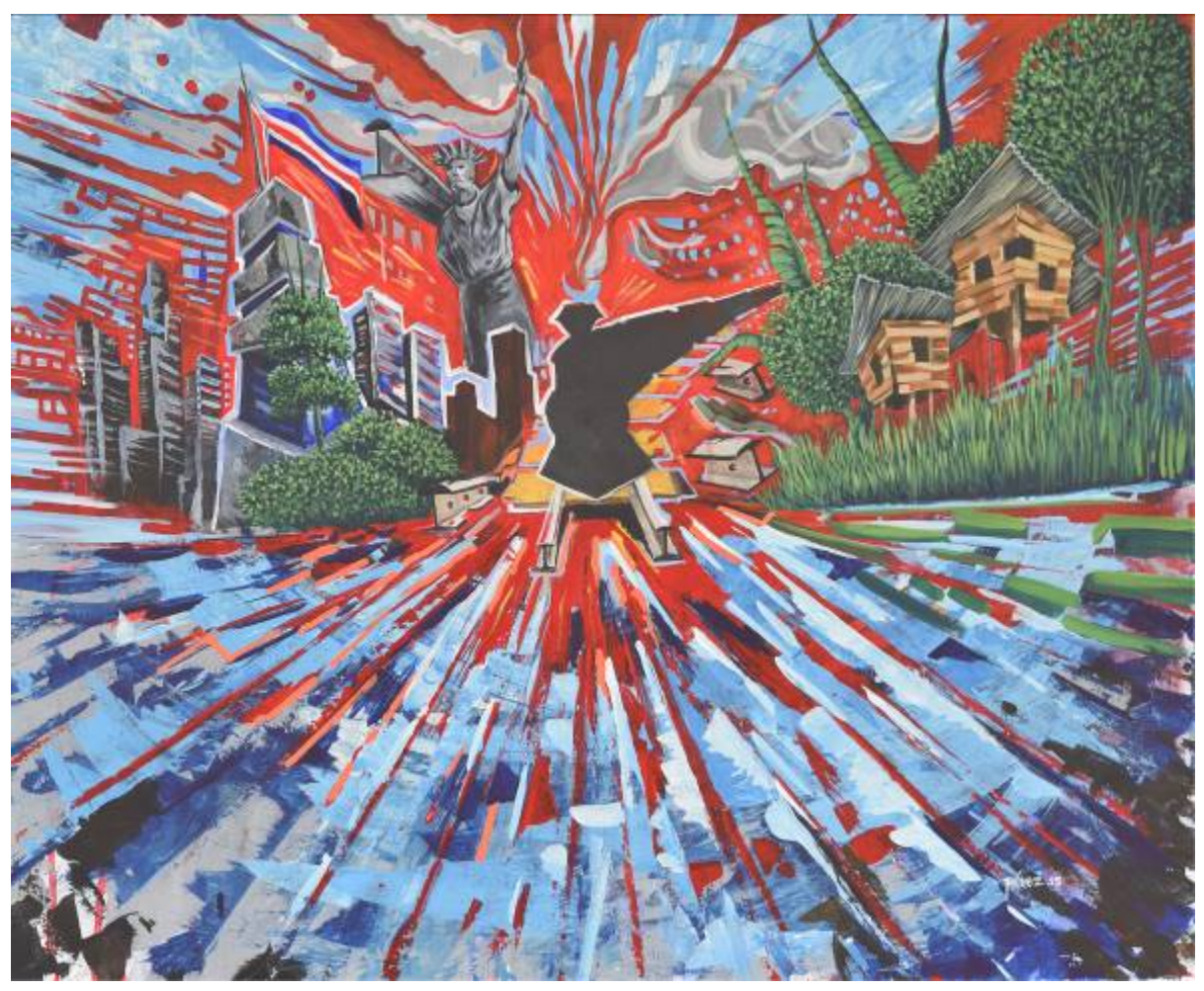

Fuente: Pérez 2015

\section{Las migraciones hacia el cantón de Pococí a partir de 1950}

En 1950, Pococí presentaba una población de poco más de 10000 habitantes, de la cual, más de la mitad procedía de otras zonas del país (Cerdas: 2013: 391). Lo anterior es muestra de que la historia de Pococí se ha escrito muy ligada a los fenómenos migratorios, ya que este cantón ha presentado particularidades en diferentes periodos, las cuales, la convierten en centro de atracción para ciudadanos de otras zonas del país. Dentro de estas particularidades destaca la actividad bananera de la United Fruit Company, que resultaba muy atractiva para trabajadores de diversos lugares del país.

Sin embargo, cuando la compañía bananera abandonó la región en la década de los treintas, devolvió al Estado parte de los terrenos que ocupó, vendió algunos otros a particulares que ya habitaban en la zona, y otros tantos los dejó en el abandono (Viales: 1998: 13). Esto fue parte de las causas que motivaron migraciones constantes hacia Pococí y el Caribe en general, pues el Estado 
incentivó a los ciudadanos de otros lugares para la tenencia de dichas tierras, por medio de los denuncios.

Por otro lado, entre 1967 y 1978 se instaló en la zona de Línea Vieja la compañía BANDECO. Esto significó el resurgimiento de la actividad bananera, y por ende la generación de nuevos empleos, que atrajeron nuevamente a personas de otros lugares del país (ProDUS 2006: 6.1-18). En tiempos más recientes, la apertura de la Ruta 32, a través del Parque Braulio Carrillo, originó una nueva oleada de migrantes en busca de oportunidades, en una zona con expectativas de desarrollo.

La artista encargada de representar este momento de la historia de Pococí, fue Ana María Granados Cáseres. La obra creada se puede apreciar en la Figura №6, para ello se empleó la técnica de dibujo a lápiz de color, y presenta unas dimensiones de 60×80 cm.

\section{Figura 6}

"Venimos de todos lados y también..."

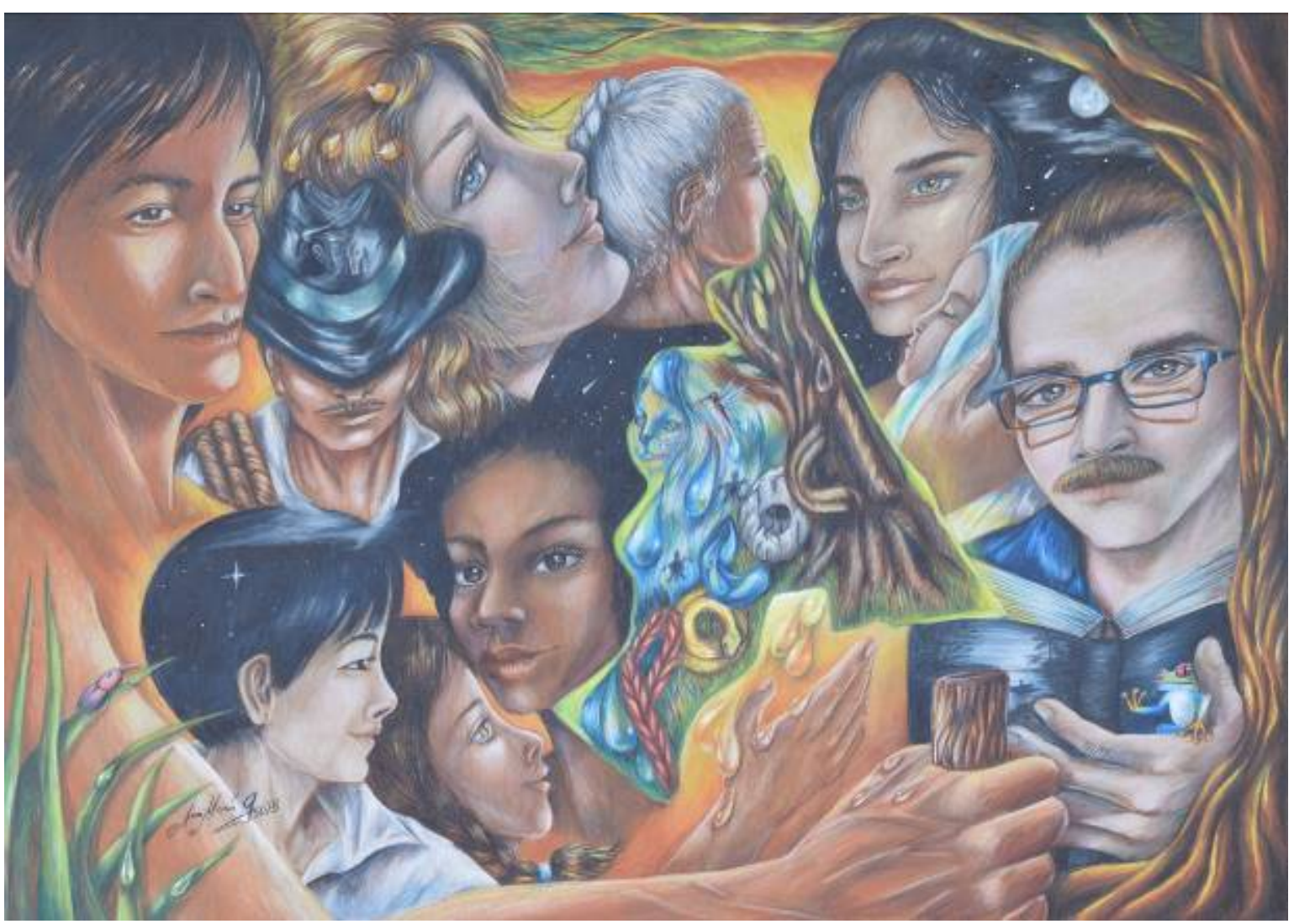

Fuente: Granados 2015 


\section{Regreso de la actividad bananera al cantón de Pococí}

En los sesentas y setentas, compañías bananeras como BANDECO y Standard Fruit Co. Introdujeron en los sectores de Pococí y Sarapiquí una nueva variedad de banano conocida como Cavendish, la cual a diferencia del Gross Michel, sí mostró una resistencia mayor a la sigatoka, mal de Panamá y al moko (Borge: 2002: 3). Esta nueva variedad dio pie a un nuevo desarrollo bananero en el cantón.

Por otro lado, el desarrollo bananero de este periodo, fue posible debido al debilitamiento de la que fuera en alguna época la poderosa United Fruit Company. Este debilitamiento implicó la participación de productores nacionales y otras empresas extranjeras en el nuevo desarrollo bananero (Kruiter: 1989: 12). Unido a lo anterior, también hubo un respaldo de parte del Estado, mediante la creación de la Ley de Fomento Bananero No.3987 del 26 de octubre de 1967 (Cerdas: 2013: 372-373). En esta ley, el sistema bancario nacional financiaba el $100 \%$ de la inversión de la siembra bananera y el Ministerio de Agricultura brindaba asesoría a los pequeños y medianos productores de las zonas bananeras. Algunas de las fincas bananeras que comenzaron a operar en el cantón de Pococí fueron, o son; Prado, Caribe, Mola, Perdiz, Los Diamantes, Coopecariari, San Pedro, Sonia y Santa Clara (Kruiter: 1989: 14).

Adicionalmente, este desarrollo bananero evolucionó con el uso de un mayor paquete tecnológico (drenado complejo, fumigación aérea, plantas empacadoras y transporte con vehículos pesados). Esto implicó un aumento de la productividad, lo cual convirtió a Pococí en el mayor productor de banano por hectárea.

En la Figura $N^{\circ} 7$ se puede observar este momento histórico representado. Dicha figura muestra la obra del artista Mauricio

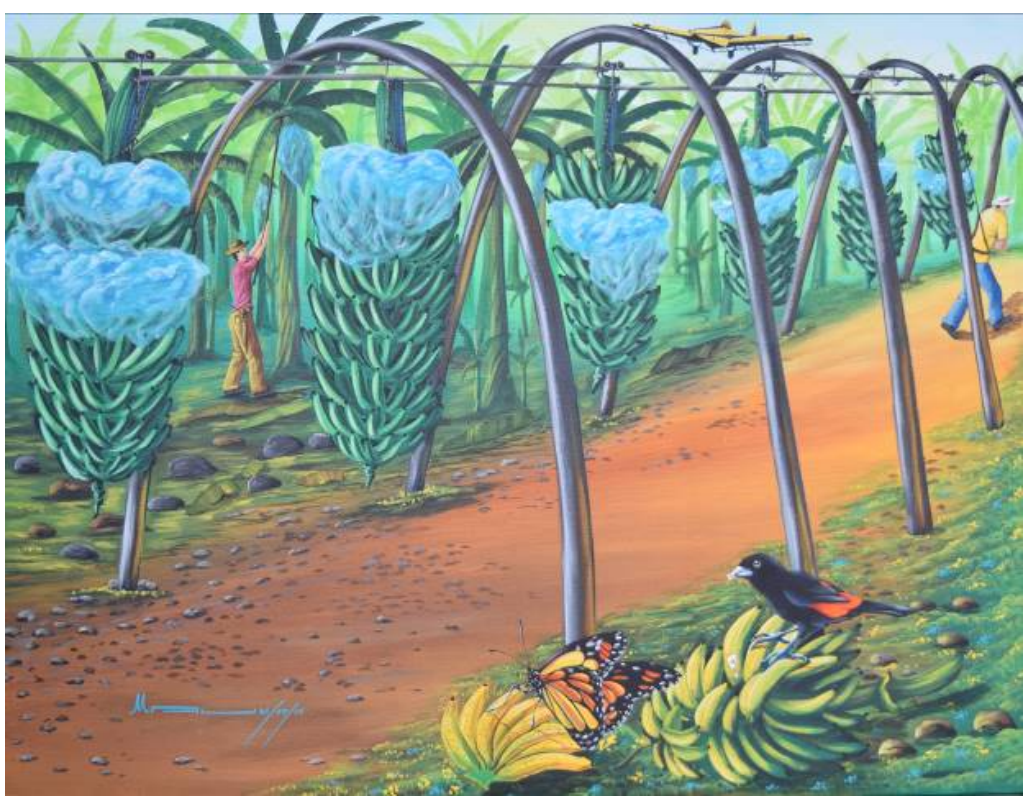

Vargas Sequeira, quien empleó una técnica de acrílico y su obra presenta dimensiones de $60 \times 80 \mathrm{~cm}$.

\section{Figura 7}

"Remembranzas de mi tierra..." 


\section{La creación de la colonia agrícola de Cariari en 1966}

En el año 1966, el entonces llamado Instituto Costarricense de Tierras y Colonización creó la "colonia" de Cariari, que se ubicó aproximadamente a 25 Kilómetros de Guápiles. Esto implicó la apertura de una nueva carretera que comunicara ambos lugares (Cerdas: 2013: 380).

Tras la creación de esta nueva colonia agrícola, se repartieron los terrenos de la Gran Reserva de AstúaPirie, y se pusieron al alcance de agricultores vastas extensiones de tierras fértiles y abundantes fuentes de agua (Jiménez: 1995: 15). Esto ocurrió en un contexto donde los gobiernos costarricenses buscaban lograr un desarrollo de la economía mediante la colonización de tierras vírgenes; es decir, tierras que aún no habían sido ocupadas por las personas. Ya para el año 1971, se crearon los distritos de Cariari, La Rita, Roxana y Colorado mediante el decreto 1825-G. (Diario Oficial La Gaceta: 1971: 12). Esto puede explicarse por el flujo creciente de pobladores que llegaron a la zona, y por el nivel de desarrollo que había alcanzado el cantón de Pococí hasta entonces. También era necesaria la apertura de nuevos caminos vecinales en los pueblos que se desarrollaron en la zona (Cerdas: 2013: 379). Así que se necesitaba la intervención del Estado desde el área administrativa. Se debe aclarar que, aunque el Estado logró repartir una porción importante de tierras, nuestros campesinos no lograron mantener la tenencia de estas. Algunas de las causas de esto son; la imposibilidad de comercializar los productos cultivados, y la venta de tierras por parte de los campesinos (Cerdas: 2013: 390). Sin dejar de lado el acaparamiento de tierras por parte de las fincas bananeras.

Este momento histórico se ve reflejado en la Figura Nㅜ8, pintada por César Chacón Quirós. El artista empleó la técnica de óleo y su pintura tiene unas dimensiones de $60 \times 80 \mathrm{~cm}$. 


\section{Figura 8}

"Bella Cariari"

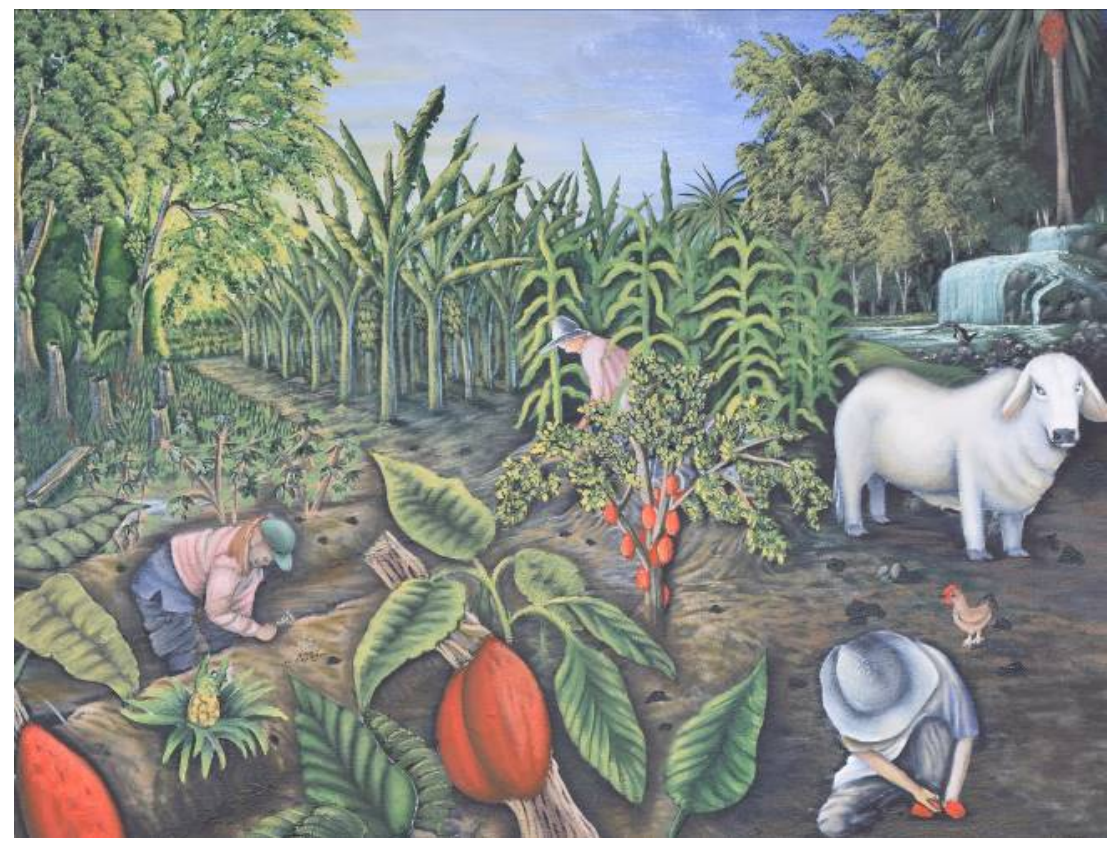

Fuente: Chacón 2015

\section{Creación del Parque Nacional Tortuguero en 1975}

El Parque Nacional Tortuguero fue creado en el año 1975 y pertenece al Área de Conservación Tortuguero. Se encuentra ubicado en la región del Caribe costarricense, $80 \mathrm{~km}$ al norte de la ciudad de Limón. La idea para crear el parque fue del herpetólogo Archie Carr II, y el motivo principal de su creación fue para proteger la tortuga verde (Cheloniamydas), ya que esta pone sus huevos principalmente en esta zona del Caribe (Mora, 2012). Además, se hizo para promover la investigación de la flora y fauna propia de la zona.

En este parque nacional se encuentran más de 400 especies de árboles y alrededor de 2200 especies de otras plantas. También habita una gran diversidad de animales, que incluye mamíferos en peligro de extinción. Por ejemplo, jaguares, manigordos, dantas, manatíes, tolomucos, perezosos y tres especies de monos, entre otros. Además, se pueden encontrar 405 especies de aves (Mora, 2012). Es importante recalcar la riqueza natural y la gran biodiversidad que existe en el cantón de Pococí. Además del prestigio que esto le aporta al cantón, ya que el Parque Nacional 
Tortuguero es visitado diariamente por una cantidad importante de turistas, tanto nacionales como extranjeros.

Paula Pamela Solano Alfaro fue la artista encargada de representar este momento histórico. Utilizó para ello una técnica de dibujo a lápiz de color. Su obra tiene unas dimensiones de $60 \times 80 \mathrm{~cm}$, y se puede ver en la Figura N9.

\section{Figura 9}

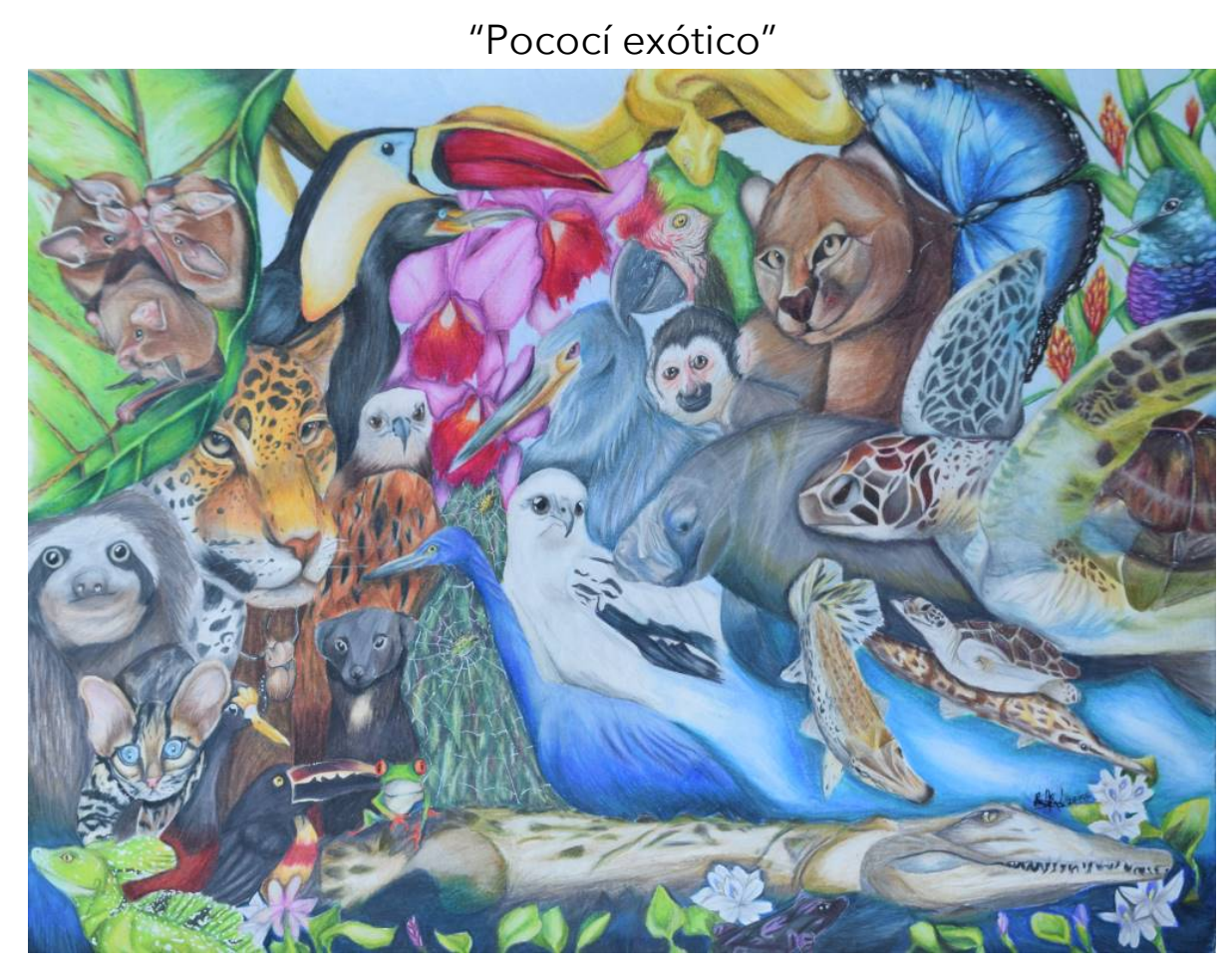

Fuente: Solano 2015

\section{El agua como recurso de desarrollo del cantón}

Como sabemos, el agua es vida y sin fuentes de agua cercanas ningún pueblo podría desarrollarse. Pococí y el cantón vecino de Guácimo cuentan con valiosas reservas de agua, que han permitido el desarrollo experimentado en los cantones. A estas fuentes o reservas se les conoce como acuíferos.

Ya desde el año 1976, la Municipalidad de Pococí gestionó la compra de fincas destinadas a proteger parte del acuífero. Pero fue hasta en la década de los ochentas cuando un grupo de vecinos se manifestó para que se declarara zona protectora de recarga acuífera, el área sur de la región (Borge: 2004: 4), especialmente porque esta área es montañosa, hecho que en un 
lugar de clima tropical lluvioso implica una importante fábrica natural de agua.

Entre 1982-1983 el Instituto Costarricense de Acueductos y Alcantarillados (AyA), realizó los primeros estudios hidrogeológicos para delimitar los acuíferos y las áreas de recarga (Borge: 2004: 5), estos son espacios donde se filtra la lluvia por el suelo y recargan los acuíferos.

El resultado de todo este proceso y de la lucha de los vecinos del cantón dio sus frutos el 15 de diciembre de 1986, cuando por medio del Decreto Ejecutivo 17390-MAG se creó la Zona Protectora Acuíferos de Guácimo y Pococí, el mismo decreto entró en vigencia a partir del 21 de enero de 1987 (Diario Oficial La Gaceta: 1987).

La creación de una zona protegida en los acuíferos del cantón de Pococí, refleja la necesidad de preservar nuestros recursos hídricos, pues se ha comprobado que el agua es un recurso no renovable. Es nuestro deber como pobladores de esta zona contribuir con la protección del agua, y estar alerta ante las actividades que puedan dañar dichos acuíferos, por ejemplo, la actividad piñera que se ha expandido y la tala ilegal de bosques protegidos.

La encargada de representar este momento fue la artista plástica Ana María Granados Cáseres. En este caso utilizó una técnica de dibujo a lápiz de color, tal como se puede apreciar en la Figura $N^{0} 10$, la cual posee unas dimensiones de $60 \times 80 \mathrm{~cm}$.

\section{Figura 10}

"La joya de Pococí"

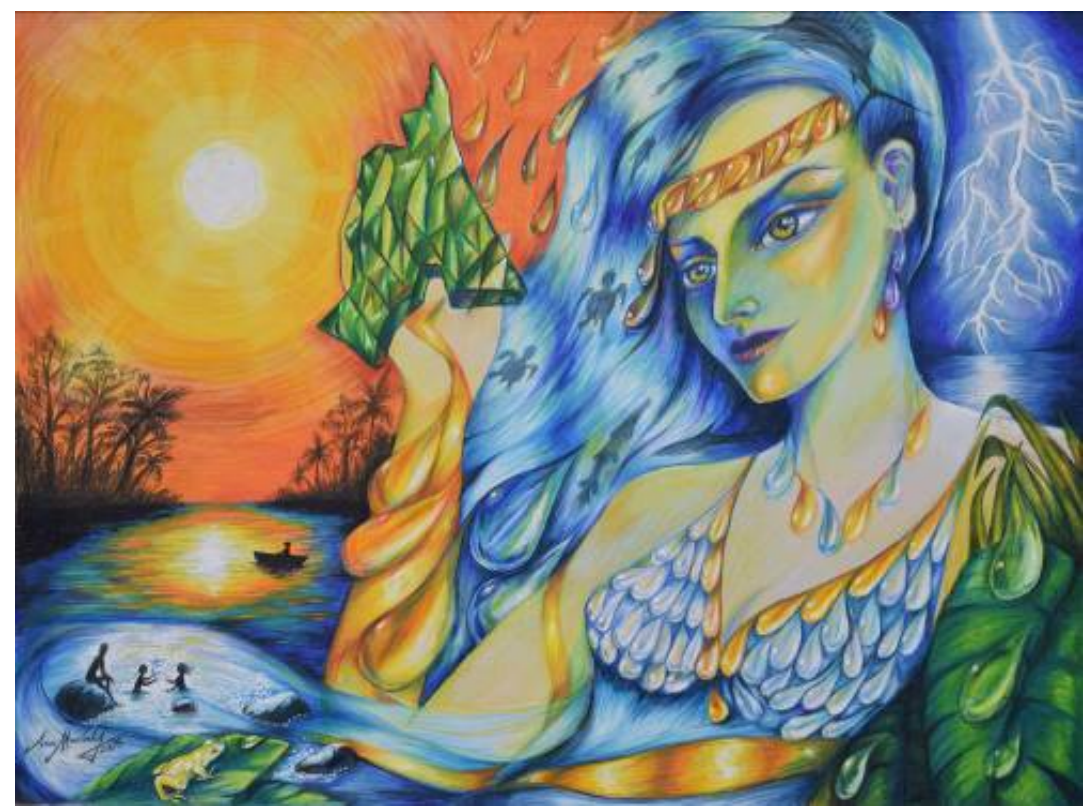

Fuente: Granados 2015 


\section{La diversificación agrícola}

El proceso denominado como la diversificación agrícola ocurre en Costa Rica en la década de los ochenta, cuando la clase gobernante decide cambiar a la política agropecuaria que atendía a los pequeños agricultores, y en el caso de nuestro cantón, eran principalmente los productores de maíz.

El cambio consistió en reducir el apoyo económico brindado a los agricultores que producían granos básicos (arroz, frijoles y maíz) que se consumían dentro del país, y apoyar a aquellos que cultivaban productos para exportar a mercados extranjeros (Korten: 1997: 18).

Estas decisiones fueron tomadas fundamentándose en la supuesta baja rentabilidad que los productos agropecuarios tradicionales le daban al sistema bancario, y en la improductividad de divisas para la importación. Adicionalmente en la alta vulnerabilidad de la región por el riesgo climático. Y por último se argumentaba que el maíz para consumo nacional era más barato importarlo (Borge: 2002: 14-15).

Esta serie de cambios en la política agropecuaria se incluyen dentro de la implementación de los Programas de Ajuste Estructural (PAEs), aprobados por la influencia de organismos financieros internacionales, como el Banco Mundial y el Fondo Monetario Internacional. Esto tuvo como consecuencia, a mediano plazo, el debilitamiento de nuestra soberanía alimentaria y la vulnerabilidad económica y social de los pequeños productores de nuestro cantón.

Para representar este momento histórico, la artista Patricia Erickson empleó la técnica de acrílico. Su obra presenta unas dimensiones de 60x80 cm, y se puede contemplar en la Figura №11. 


\section{Figura 11}

"Los frutos de nuestro terruño"

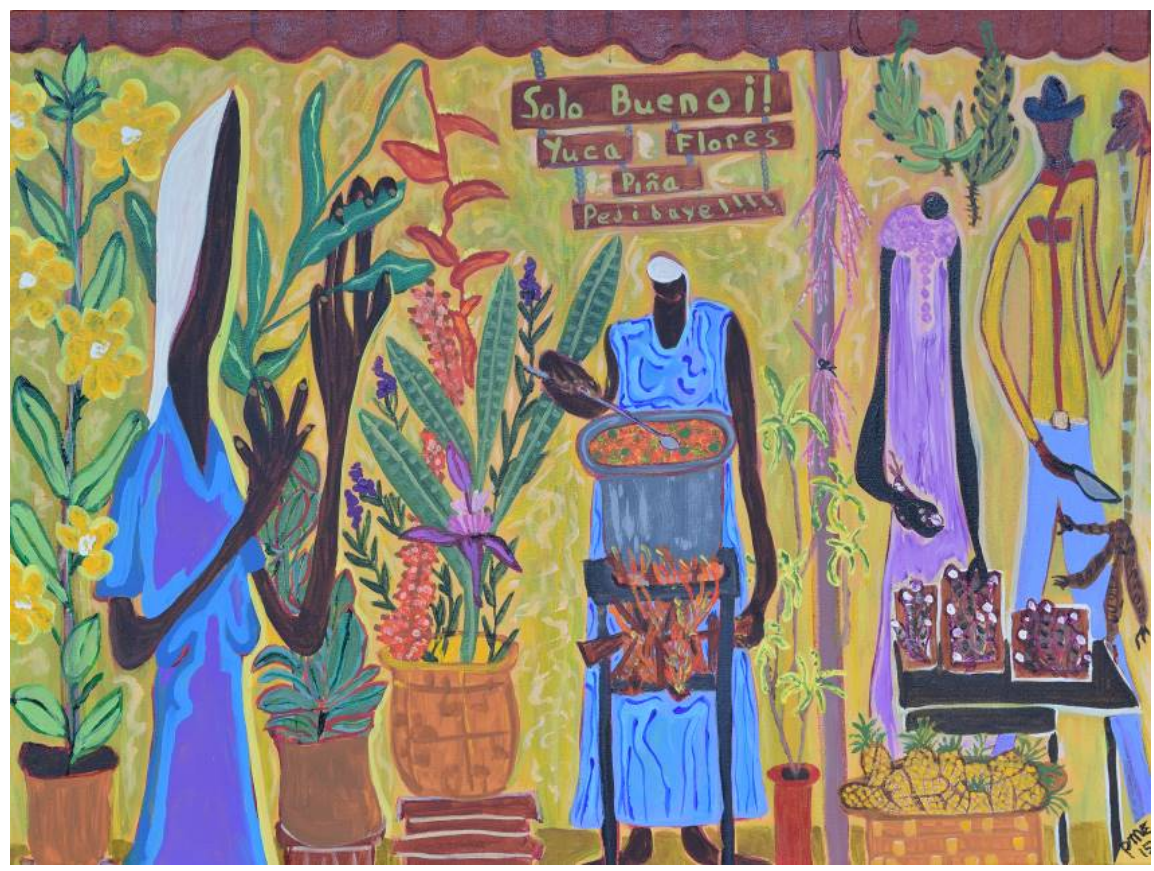

Fuente: Erickson 2015

\section{Construcción de la Ruta 32}

El 28 de marzo de 1987, durante la administración del presidente Óscar Arias Sánchez, se inauguró la Ruta 32 sobre el Parque Nacional Braulio Carrillo (La Nación: 1987: 6A). Dicha ruta conectó el cantón de Pococí con el Valle Central. Recordando que, con la apertura de esta carretera se cumplió un objetivo planteado desde el siglo XIX, y por el cual se dieron muchas luchas y manifestaciones de pobladores de Pococí (Jiménez: 1995: 30-37).

Las principales causas que impulsaron las demandas por una ruta que conectara el Valle Central con el Atlántico fueron: la necesidad de comercializar los productos en el Valle Central (Cerdas: 2013: 378); y el acceso a los diferentes servicios públicos gubernamentales que se ofrecían mayoritariamente en la capital (Arias, 2011) -por ejemplo, hospitales, ministerios del gobierno y educación superior-, dada la poca presencia del Estado en el cantón de Pococí.

No obstante, a pesar de la construcción de esta carretera (que sin lugar a duda fue muy importante para Pococí), las promesas de desarrollo y progreso no se cumplieron con igualdad para todos 
los habitantes del cantón. Siendo los pequeños agricultores los menos beneficiados, pues se frustraron sus deseos de poseer tierras y obtener ingresos por la comercialización de sus productos. El artista encargado de representar este momento de la historia de Pococí fue José Alberto Pérez Arrieta, cuyo nombre artístico es "Copetilla". Su producto final puede apreciarse en la Figura №12, para la cual utilizó la técnica de acrílico, esta presenta unas dimensiones $60 \times 80 \mathrm{~cm}$.

Figura 12

"Tamandúa con cría en Ruta 32"

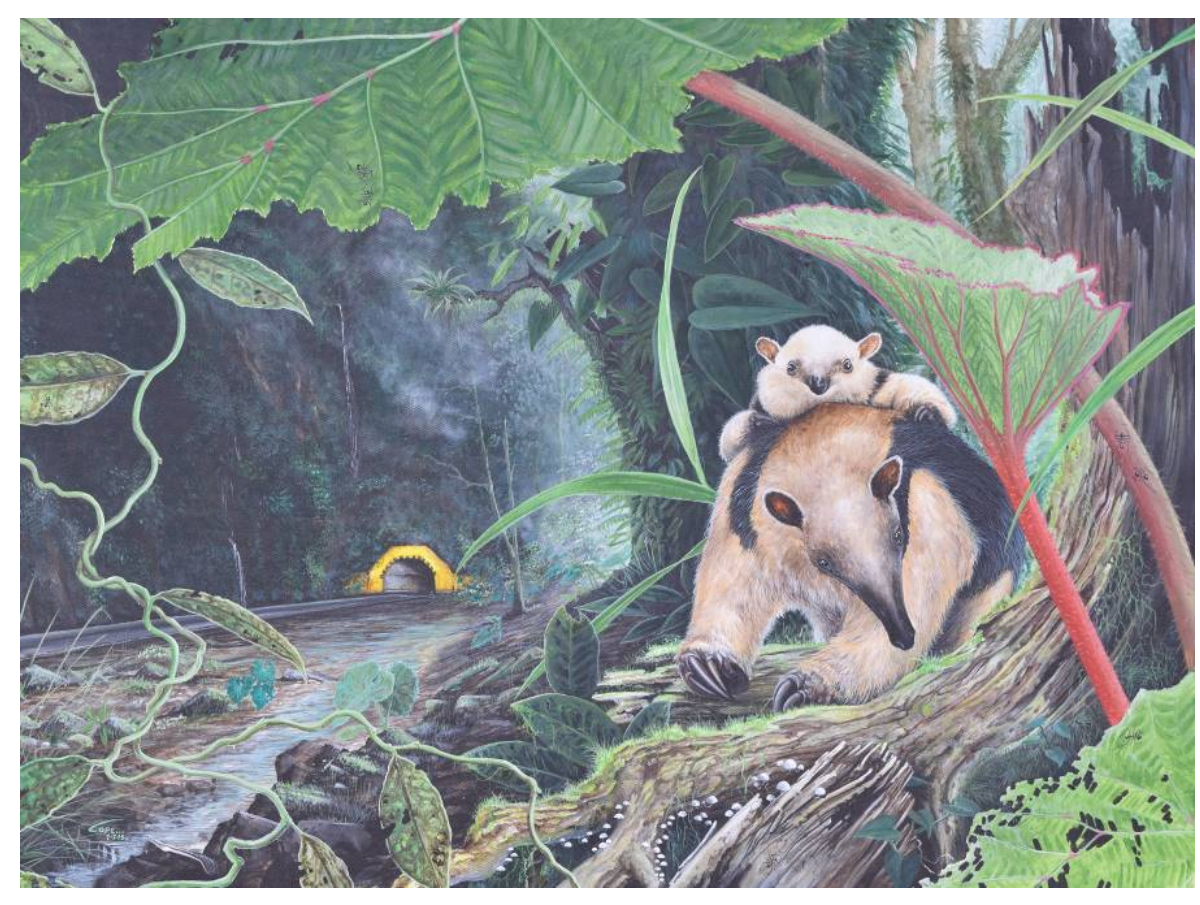

Fuente: Pérez 2015

\section{CONCLUSIONES}

En primer lugar, se detectó el vacío existente en la población cantonal acerca de las raíces culturales e históricas de Pococí, el cual se espera llenar con la exposición itinerante de la galería histórica presentada en este artículo. Por otro lado, se logró el cumplimiento del objetivo planteado con respecto a la visualización de los artistas plásticos ubicados en el cantón de Pococí, por parte de la comunidad. También una visualización de sí mismos como un colectivo que lucha por el fomento de las artes plásticas en la comunidad. Además, se logró la recopilación de diferentes materiales históricos que permitirán generar otros 
productos de naturaleza didáctica, para ser empleados en la trasmisión de una parte del conocimiento histórico sobre Pococí. Lo anterior, tomando en cuenta la importancia de fomentar una diversidad cultural y el fortalecimiento identitario autóctono de los habitantes de Pococí, en aras de contribuir a un desarrollo más integral. Por eso, se recomienda la generación de iniciativas innovadoras que sigan contribuyendo, a partir de las artes, al fortalecimiento de la identidad cultural local. Dichas iniciativas deben orientarse principalmente al sector de la población más joven, la cual, será la que en el futuro tendrá a cargo el desarrollo del cantón.

\section{BIBLIOGRAFÍA}

Araya, Heriberto. (2014). "¡Sabía Usted Que! Historia De La Escuela Central De Guápiles". Diario El Independiente. Consultado En: Http://Www.Elindependiente.Co.Cr/2014/04/Sabia-Usted-Que-HistoriaDe-La-Escuela-Central-De-Guapiles/

Arias, Dennis. (2011). "Progreso O Tristeza: Una Historia, O No, Del Caribe Costarricense (Pococí 1911-1990)". Asociación Para El Fomento De Los Estudios Históricos En Centroamérica 48. Consultado En: Http://Www.Afehc-Historia-

Centroamericana.Org/?Action=Fi_Aff\&ld $=2585$

Borge, Carlos. (2002)."Rumbos Nuevos Para Línea Vieja: Un Análisis De La Historia, El Presente Y El Futuro De La Región De Pococí, Guácimo Y Horquetas". Manuscrito. En Archivo. SEDER. Costa Rica.

(2004). Informe Final. Seminario El Acuífero Es De Todos: Una Agenda Común. Manuscrito En Archivo. Proyecto COBODES. Costa Rica.

Cerdas, Rosa. (2013). "Evolución De La Estructura Productiva Del Cantón De Pococí En El Periodo De 1950-1984", La Conformación Histórica De La Región Atlántico/Caribe Costarricense: $(R e)$ Interpretaciones Sobre Su Trayectoria Entre El Siglo XVI Y EI Siglo XXI, Pp. 361-405. Editorial Nuevas Perspectivas, San José.

Diario oficial la gaceta. 15 De Julio De 1971. No.144. San José, Costa Rica.

Rica. 
La Nación. 29 De Marzo De 1987. "Guápiles Se Echó A La Calle". San José, Costa Rica.

Hernández, Grace. (2012). Pococí Con Nuevo Distrito. Municipalidad De Pococí. Consultado En:

Http://Munipococi.Go.Cr/New.Php?ld=9\#.Viajag6dzry

Ibarra, Eugenia. (1986). La Desestructuración Del Cacicazgo En El Siglo XVI Y Su Relación Con El Proceso De Conquista: Una Perspectiva De Su Organización Social. Revista De Historia 12-13: 85-103. Consultado En: Http://Www.Revistas.Una.Ac.Cr/Index.Php/Historia/Article/View/3191

Instituto Nacional de Estadística y Censo. (2011). X Censo Nacional De Población Y VI De Vivienda 2011. Resultados Generales. INEC, San José.

Jiménez, Reinaldo. (1995). A Guápiles Con Cariño. Inversiones OGGA, San José.

Korten, Alicia. (1997). Ajuste Estructural En Costa Rica. Una Medicina Amarga. Editorial Departamento Ecuménico De Investigaciones, San José.

Kruiter, a.h. (1989). El Banano En El Norte De La Zona Atlántica De Costa Rica. CATIE, Turrialba.

Larraín, Jorge. (2003). "El Concepto De Identidad". Revista FAMECOS, Porto Alegre 21: 30-42. Consultado En: Http://Revistas.Univerciencia.Org/Index.Php/Famecos/Article/Viewfile/34 $8 / 279$

Le Goff, Jacques. (2005). Pensar La Historia. Modernidad, Presente, Progreso. Litografía Rosés, S.A., España.

Molano, Olga. (2007). "Identidad Cultural Un Concepto Que Evoluciona". Revista Opera 7: 69-84. Consultado En: Http://Www.Redalyc.Org/Articulo.Oa?ld=67500705

Mora, José. (2012). Parque Nacional Tortuguero. Consultado En: Http://Www.Acto.Go.Cr/Index.Php/Es/Areas-Protegidas/Parque-

Nacional-Tortuguero

Municipalidad de Pococí. (2013). Plan Desarrollo Humano Cantonal. Consultado En: Http://Munipococi.Go.Cr/Section.Php?ld=30

Pereyra, Carlos Et Al. (2005). Historia ¿Para Qué? Siglo XXI Editores, S.A. De C.V, México. 
Programa de Desarrollo Urbano Sostenible de la Universidad de Costa Rica (Produs). (2006). Diagnóstico Plan Regulador De Pococí, Tomo I. Universidad De Costa Rica, San José.

(2006). Diagnóstico Plan Regulador De Pococí, Tomo II. Universidad De Costa Rica, San José.

Sáenz, Manuel. (1911). Los Ferrocarriles En Costa Rica. Imprenta Del Comercio, San José.

Solórzano, Juan Carlos. (1997). "Indígenas Insumisos, Frailes Y Soldados: Talamanca Y Guatuso, 1660-1821". Anuario De Estudios Centroamericanos 23 (1-2): 143-197. Consultado En: Http://Revistas.Ucr.Ac.Cr/Index.Php/Anuario/Article/View/1822/1791

UNESCO. (2004). Declaración Universal Sobre La Diversidad Cultural. Representación De UNESCO En Perú, San Borja.

UNESCO ETXEA. (2010). Cultura Y Desarrollo. Evolución Y Perspectivas. Cuadernos De Trabajo N¹. SRB, España.

Viales, Ronny. (1998). Después Del Enclave. Un Estudio De La Región Atlántica Costarricense. Editorial UCR, San José.

(2013). "La Segunda Colonización De La Región Atlántico/Caribe Costarricense. Del Siglo XVI Hasta La Construcción De La Red Ferroviaria", La Conformación Histórica De La Región Atlántico/Caribe Costarricense: $(R e)$ Interpretaciones Sobre Su Trayectoria Entre EI Siglo XVI Y EI Siglo XXI, Pp.89-126. Editorial Nuevas Perspectivas, San José.

Viales, Ronny y Montero, Andrea. (2014). "Agriculturización Y Cambios" En El Paisaje. El Banano En El Atlántico/Caribe De Costa Rica (1870-1930). HALAC 3: 310-338. 
Revista Herencia, Vol. 29 (2), julio-diciembre, 2016. 